\title{
Chapter 2 \\ Do Measures of Parenting Have the Same Meaning for European, Chinese, and Filipino American Adolescents? Tests of Measurement Equivalence
}

\author{
Lisa J. Crockett, Glen J. Veed, and Stephen T. Russell
}

As outlined in Chapter 1, intriguing differences between European Americans and Asian Americans have emerged in earlier studies of parenting. According to these studies, Asian American parents are more restrictive and control-oriented and express less overt warmth than European American parents (Bond \& Wang, 1983; Chiu, 1987; Lin \& Fu, 1990; Wu \& Chao, 2005). However, most of the work to date has focused on Chinese American samples and less is known about other Asian groups, such as Filipino Americans, although recent studies have begun to fill this gap (Agbayani-Siewert, 1994; Fuligni \& Pedersen, 2002; Pe-Pua \& Protacio-Marcelino, 2000).

There is reason to suspect that the meaning of some parenting practices differs cross-ethnically owing to distinct parenting philosophies and cultural norms (Chao, 1994; Lansford et al., 2005). For example, the meaning of control behaviors may vary among Chinese-, Filipino-, and European Americans: they may be viewed more positively by Asian American cultural groups, especially Chinese Americans (Lau, Lew, Hau, Cheung, \& Berndt, 1990; Nomura, Noguchi, Saito, \& Tezuka, 1995). Thus, Chinese and Filipino adolescents may be more likely to interpret parental control behaviors as a form of caring and to accept these behaviors as legitimate (Fuligni, 1998; Lam, 2003). Furthermore, the behaviors that signal parental support may differ across cultural groups, with direct expressions of warmth and affection being more central to European Americans' than to Asian Americans' conceptions of support (Chao, 2001a; Wu \& Chao, 2005). If so, direct expressions of warmth might be less relevant to Asian American teenagers' perceptions of being loved and supported. The differing interpretations of parental control and support raise the possibility that Asian Americans and European Americans hold distinct notions of parenting. Furthermore, Chinese American and Filipino American adolescents might differ from each other in their understanding of parental support and control. Filipino Americans are less likely than Chinese Americans to emphasize traditional Asian cultural values perhaps

\footnotetext{
L.J. Crockett $(\bowtie)$

University of Nebraska, Lincoln, NE, USA

e-mail: ecrockett1@unl.edu
} 
owing to the extended history of Spanish and US influence in the Philippines and the influence of Catholicism. Such differences could lead to subtle or not so subtle differences in socialization goals, parenting norms, and children's interpretation of parental behaviors.

Cultural perspectives on parenting support the notion of cultural differences in the meaning of parenting behaviors. Value orientations and associated "cultural scripts" inform parenting practices and parent-child relationships, as well as family members' understandings of their relationships (Greenfield, 1994). More broadly, parenting practices reflect parents' ethnotheories (or cultural beliefs about parenting and child development; Super \& Harkness, 1986) and cultural notions of desirable human characteristics. Presumably these ethnotheories and values are transmitted to children in the course of socialization. Thus, cultural values and scripts constitute an important frame of reference for children's expectations regarding parent-child relationships and interpretations of parents' behavior.

Such differences in conceptions of parenting pose challenges for measuring parenting behaviors across different ethnic groups. If parental support (or control) encompasses different behaviors among European Americans than Chinese Americans, a scale designed to measure that construct in one group is likely to omit behaviors that are important for defining it in the other group, resulting in different levels of the validity of that measure for the two cultural groups. Moreover, even if the same items (behaviors) are relevant in both groups, they may be interpreted somewhat differently or may be more central to one group's understanding of the construct than the other's. Such differences can result in differential measure validity and distinct measurement properties in the two groups. It follows that use of such a measure in cross-cultural or cross-ethnic work could lead to inaccurate inferences about group differences in parental support or its effects. For this reason, measures that have been developed primarily from the perspective of one cultural or ethnic group need to be examined and validated in other groups before cross-cultural comparisons are made. Most measures of parenting have been developed primarily with European American samples (Julian, McHenry, \& McKelvey, 1994), and the question of measurement equivalence for Asian populations - or the degree to which a measure of parenting has the same meaning or is "equivalent" across groups-has rarely been addressed. Unless measurement equivalence is established, it is difficult to determine whether ethnic differences in scores reflect true differences in parenting or differences in the meaning of the parenting measures.

From another perspective, an examination of measurement equivalence can provide information on cross-cultural similarities and differences in conceptions of parenting. A lack of equivalence in measures may indicate differences between groups in the meaning or importance of particular parenting behaviors. For example, a measure of autonomy granting (i.e., low levels of parental control) that exhibits a different factor structure among Filipino Americans and Chinese Americans may indicate different clusters of parenting behaviors or dimensions of parental control experienced in each group. Thus, finding measurement equivalence increases confidence in a parenting measure but also provides evidence supporting cross-cultural similarities in the parenting constructs under study. Conversely, a failure to find 
measurement equivalence makes cross-cultural comparisons suspect and may also point to cultural differences in the interpretation or salience of particular parenting behaviors.

In this chapter, we investigate the cross-ethnic equivalence of parenting measures using data from the National Longitudinal Study of Adolescent Health (Add Health Study). The "Add Health" Study was begun in the mid-1990s and is the largest, most comprehensive study of adolescents in the United States. The study is unique because it includes a range of measures about parenting and parent-adolescent relationships. In addition, the original in-home survey involved over 20,000 US adolescents, and included a specific over-sample of Chinese American adolescents. Thus, the study allows us to examine adolescents' reports of their relationships with their parents and their parents' parenting behaviors for over 8,550 European American, 250 Chinese American, and over 450 Filipino American adolescents. Our analyses were designed with two goals in mind: first, to learn whether the measures of parental support and control (framed as autonomy granting) show measurement equivalence/invariance and, second, to gain insight into the different understandings of parental support and autonomy granting held by Chinese American, Filipino American, and European American adolescents.

\section{How Similar Are Measures Across Ethnic Groups?}

Lack of measurement equivalence can occur for several reasons (Hui \& Triandis, 1985; Knight \& Hill, 1998). At the most basic level, there may be a lack of construct equivalence, such that each group conceptualizes parental support differently (Crockett, Randall, Shen, Russell, \& Driscoll, 2005; Hui \& Triandis, 1985). If so, a measure of parental support developed for one group (e.g., European Americans) would fail to capture relevant aspects of support as understood by the other group (e.g., Filipino Americans). Even if the construct is the same in both groups, the measure utilized could assess that construct more poorly in one group than the other, making scores for that group less accurate. Finally, for a given measure, different groups may interpret the possible response options differently or utilize a different metric when answering, resulting in a lack of scalar equivalence (Hui \& Triandis, 1985). In such cases, a particular score would reflect different amounts of the construct in the two groups (e.g., an identical score might indicate high parental support in one group but only moderate parental support in another). For example, if Asian Americans are less likely than European Americans to endorse positively worded questions (Bae \& Brekke, 2003), we would expect to see ethnic differences in perceived parenting even if actual levels of parenting behaviors are the same. The problem of measurement nonequivalence also extends to heterogeneity within racial or ethnic groups, in this case Asian Americans. Chinese Americans and Filipino Americans represent distinct nationalities, historical influences, and cultural traditions, which may influence each group's normative patterns of parenting, their understandings of parental support and autonomy granting, and their responses to parenting measures. 
Studies of measurement equivalence typically include an assessment of factorial invariance across groups (Vandenberg \& Lance, 2000), that is, whether the scale that is used by respondents is comparable across groups. The assessment of factorial invariance is based on multi-group confirmatory factor analysis (CFA). A series of models is tested in which progressively stricter constraints are added, reflecting increasingly stringent levels of cross-group invariance. First, configural invariance is examined to see whether a set of items are related in similar ways across groups: do the same items form a cluster or factor in each ethnic group? If configural invariance is supported, weak (metric) invariance is examined (equality of factor loadings across groups): do the items have the same relative contribution to the measure across groups? If weak or metric invariance can be established, the next step is to test for strong (scalar) invariance (equality of item intercepts as well as factor loading across groups): are the average scores on each item in the measure equal across groups? Finally, if metric and scalar invariance can be established, the final step is to test for strict invariance (equality of unique item error variances as well as factor loadings and intercepts across groups): if the loading and average score for each item are the same for each group, is the error variance the same across groups as well? The fit of the model after each new constraint is added is compared to that of the preceding model using a chi-square difference test: significant increases in $\chi^{2}$ indicate a decrement in model fit and a lack of invariance. Partial invariance is also possible at each stage, where some but not all items are invariant across groups (Byrne, Shavelson, \& Muthén, 1989; Vandenberg \& Lance, 2000).

We examined the factorial invariance of Add Health measures of parental support and autonomy granting in order to assess the equivalence of these measures for European American, Chinese American, and Filipino American boys and girls and, further, to explore whether adolescents in these three ethnic groups have similar understandings of parental support and autonomy. Analyses were conducted separately for girls and boys, and separate measures of maternal and paternal support were included because other research indicates that children's perceptions of their relationships with parents depend on both the gender of the adolescent and the gender of the parent (Berndt, Cheung, Lau, \& Hau, 1993; Crockett, Brown, Russell, \& Shen, 2007; Crockett, Brown, Iturbide, Russell, \& Wilkinson-Lee, 2009; Youniss \& Smollar, 1985).

\section{Method}

\section{Sample}

The National Longitudinal Study of Adolescent Health (Add Health) was designed to examine the health status of adolescents, as well as influences on their healthrelated behaviors. The study includes a nationally representative sample of US adolescents in grades 7-12 based on a multistage, stratified, school-based, cluster sampling design. Specifically, a sample of 80 high schools and 52 middle schools from the United States (132 schools) was selected to be representative of US schools 
with respect to region of country, urbanicity, school type, ethnicity, and school size (Udry, 1998). The students in those schools were invited to participate.

Students who completed an in-school questionnaire or who were listed on a school roster of one of the participating schools were eligible to complete an InHome Interview. A representative sample of these youth (the core sample) was selected and supplemented with several subsamples. Some ethnic groups were sampled in proportion to their size within the US population, whereas others (e.g., Chinese Americans, Cuban Americans, Puerto Ricans) were oversampled to ensure adequate sample sizes for analysis (Bearman, Jones, \& Udry, 1997). The survey was conducted in English; thus non-English-speaking Asian American adolescents would be under-represented in our analyses.

The sample for the present analysis was based on over 20,000 adolescents who completed the first In-Home Interview (Wave 1; contractual data set). To be included in the present analysis, adolescents had to be between the ages of 12 and 18 at Wave 1, have valid sample weights, and self-identify as non-Hispanic White (European American), Chinese, or Filipino. If more than one adolescent in a family participated, one sibling was randomly selected for inclusion in order to eliminate potential dependency in the data. The final analytic sample included 9,262 youth (51\% female): 8,550 European Americans, 253 Chinese Americans, and 459 Filipino Americans. The sample size for analyses of paternal support was substantially smaller than for other parenting variables because data on paternal support was obtained only from adolescents with a resident father. Otherwise, the amount of missing data was trivial, resulting in the loss of no more than 12 cases for any particular subgroup in the analysis.

\section{Measures}

Racelethnicity. Respondents were classified into racial/ethnic groups based on their responses to four questions. Race was based on two questions: (1) "What is your race?" and (2) "Which one category best describes your racial background?" (For each question, the response options were: White, Black or African American, American Indian or Native American, Asian or Pacific Islander). Ethnicity was based on a third question, "Are you of Hispanic or Latino origin?" (no, yes). Finally, Asian adolescents were asked, "What is your Asian background?" Non-Latinos were selected for the present analysis. They were classified as European American if they endorsed "White" as their only race or as the category that "best" described their racial background; they were classified respectively as Chinese American or Filipino American if they selected Asian as their only or best racial background and then selected Chinese American (Filipino American) as their Asian origin.

Perceived maternal and paternal support. For each resident parent, adolescents responded to five items indexing the level of parental warmth and caring:

1. How close to you feel to your mother [father]?

2. How much do you think she [he] cares about you? 
3. Most of the time, your mother [father] is warm and loving to you.

4. You are satisfied with the way your mother [father] and you communicate with each other.

5. Overall, you are satisfied with your relationship with your mother [father].

For the first two questions, response options ranged from 1 (not at all) to 5 (very much); for the remaining questions, responses ranged from 1 (strongly disagree) to 5 (strongly agree). Because support from non-resident fathers was not assessed in the Add Health survey, only adolescents with resident fathers were included in analyses of paternal support.

Perceived parental autonomy granting. Parental autonomy granting was assessed by asking adolescents whether their parents allowed them to make their own decisions in six areas. Possible responses were 0 (no) or 1 (yes). Specifically, adolescents were asked, "Do your parents let you make your own decisions about":

1. the people you hang around with?

2. what you wear?

3. how much television you watch?

4. which television programs you watch?

5. what time you go to bed on weeknights?

6. what you eat?

\section{Analytic Approach}

We examined the factorial invariance of the three parenting measures (maternal support, paternal support, and autonomy granting) using confirmatory factor analysis (CFA) in MPlus. A series of CFAs was conducted separately by gender to examine configural, weak, strong, and strict factorial invariance. First, to investigate configural invariance, we tested the fit of a one-factor solution of each parenting measure separately for European Americans, Chinese Americans, and Filipino Americans of each gender. If the model showed adequate fit in two ethnic groups (e.g., European American and Filipino American boys), cross-ethnic configural invariance was supported for those groups.

If configural invariance between two ethnic groups was supported, we used multigroup CFA to examine weak, strong, and strict factorial invariance across those two groups. Following recommendations outlined by Vandenberg and Lance (2000), a series of two-group models was tested to examine the effect of constraining specific parameters to be equal across groups. In the first (unconstrained) model, factor loadings, item intercepts, and item error variances were allowed to vary across groups (Model 1). In the second model (weak invariance), corresponding factor loadings were constrained to be equal across the two groups (Model 2). If weak invariance was supported, we proceeded to examine strong invariance by constraining corresponding item intercepts as well as factor loadings to be equal across groups (Model 3). Finally, if strong invariance was supported, we examined strict invariance 
by further constraining corresponding item error variances to be equal across groups (Model 4).

To assess model fit, we used the Satorra-Bentler scaled chi square, which is based on a maximum likelihood estimator with robust standard errors (MRL in MPlus; also known as the Yuan-Bentler T2 statistic [Yuan \& Bentler, 2000]). Because the chi-square test is sensitive to sample size (Kline, 1998), we also examined other fit indices including the Comparative Fit Index (CFI), the Root Mean Squared Error of Approximation (RMSEA), and the Standardized Root Mean Square Residual (SRMR). Adequate fit was indicated by a CFI greater than 0.90 and RMSEA and SRMR less than 0.10 (Jöreskog \& Sörbom, 1998; Kelloway, 1998; Kline, 1998; Maruyama, 1998). A chi-square difference test, calculated as recommended by Muthén and Muthén (1998-2007), was used to compare the fit of successive models (e.g., Model 1 and Model 2). A significant increase in the chi-square value indicates a decrement in model fit, and this change in fit was the basis for assessing factorial invariance. For example, if constraining corresponding factor loadings to be equal across groups did not result in a significant increase in the chi-square value when compared to the unconstrained model, weak factorial invariance was supported. However, if the chi-square value was significantly larger once corresponding factor loadings were constrained to be equal across groups, the significant decrement in model fit indicated that weak invariance was not supported. If invariance was not supported at any stage, tests of partial metric invariance were conducted to see whether a subset of items was invariant (Byrne et al., 1989; Kline, 1998; Vandenberg \& Lance, 2000).

In the Add Health study, schools were sampled and adolescents in those schools recruited. Because adolescents from the same school are more similar to each other than they are to adolescents from other schools, the sample is subject to a clustering effect. In addition, certain groups of adolescents were oversampled to ensure adequate sample sizes for analysis. Sample weights are applied to ensure that the sample represents the national population. Failure to take these aspects of the sampling design into account will lead to inaccurate point estimates and standard errors, biasing results toward finding differences between groups (Chantala \& Tabor, 1999). To avoid this problem, CFAs were conducted in Mplus, which can adjust for both sample weights and clustering effects (Muthén \& Muthén, 19982007). All CFAs included sample weights and accounted for the clustered design. In contrast, descriptive statistics were estimated using SAS; these analyses included sample weights but did not adjust for the clustering effect.

\section{Results}

Demographic characteristics of the analytic sample based on weighted data are provided in Table 2.1 (these descriptive analyses were conducted in SAS and did not adjust for the complex sample design). The ethnic subsamples included roughly equal numbers of boys and girls. On average, parent education differed significantly across ethnic groups. Filipino girls reported higher levels of maternal education and 
Table 2.1 Means (standard errors) or percentages for demographic variables, parental support, and autonomy measures by ethnic group and gender

\begin{tabular}{|c|c|c|c|c|c|c|}
\hline & \multicolumn{2}{|c|}{ European American } & \multicolumn{2}{|c|}{ Filipino American } & \multicolumn{2}{|c|}{ Chinese American } \\
\hline & $\begin{array}{l}\text { Boys } \\
(N=4,132)\end{array}$ & $\begin{array}{l}\text { Girls } \\
(N=4,418)\end{array}$ & $\begin{array}{l}\text { Boys } \\
(N=234)\end{array}$ & $\begin{array}{l}\text { Girls } \\
(N=225)\end{array}$ & $\begin{array}{l}\text { Boys } \\
(N=135)\end{array}$ & $\begin{array}{l}\text { Girls } \\
(N=118)\end{array}$ \\
\hline Age & $15.38(0.03)^{\mathrm{a}}$ & $15.27(0.03)^{\mathrm{a}}$ & $15.59(0.11)$ & $15.83(0.12)$ & $15.57(0.14)$ & $15.24(0.16)$ \\
\hline $\begin{array}{l}\text { Maternal } \\
\text { education }\end{array}$ & $5.58(0.04)^{\mathrm{a}}$ & $5.55(0.03)^{\mathrm{b}}$ & $5.91(0.18)$ & $6.45(0.17)^{a, b}$ & $5.21(0.24)$ & $6.58(0.26)$ \\
\hline $\begin{array}{l}\text { Paternal } \\
\text { education }\end{array}$ & $5.74(0.04)^{\mathrm{a}}$ & $5.73(0.04)^{\mathrm{b}}$ & $6.15(0.17)$ & $6.36(0.17)$ & $5.45(0.28)$ & $7.23(0.25)^{\mathrm{a}, \mathrm{b}}$ \\
\hline $\begin{array}{l}\text { Financial } \\
\text { problems }\end{array}$ & $12 \%$ & $13 \%$ & $9 \%$ & $14 \%$ & $9 \%$ & $1 \%$ \\
\hline $\begin{array}{l}\text { Maternal } \\
\text { support }\end{array}$ & $4.49(0.01)^{\mathrm{a}, \mathrm{b}, \mathrm{c}}$ & $4.38(0.01)^{\mathrm{a}}$ & $4.50(0.04)^{\mathrm{d}}$ & $4.20(0.05)^{\mathrm{c}, \mathrm{d}}$ & $4.15(0.04)^{\mathrm{b}}$ & $4.40(0.05)$ \\
\hline $\begin{array}{l}\text { Paternal } \\
\text { support }\end{array}$ & $4.31(0.01)^{\mathrm{a}, \mathrm{b}, \mathrm{c}}$ & $4.22(0.01)^{\mathrm{a}}$ & $4.32(0.05)$ & $4.02(0.06)^{\mathrm{c}}$ & $3.91(0.08)^{b}$ & $4.32(0.07)$ \\
\hline Autonomy & $4.97(0.02)^{\mathrm{a}}$ & $5.13(0.02)^{\mathrm{a}, \mathrm{b}}$ & $4.72(0.12)$ & $4.47(0.13)^{\mathrm{b}}$ & $4.69(0.14)$ & $4.85(0.16)$ \\
\hline
\end{tabular}

Note: Maximum $N$ is listed; N's varied across measures due to missing values. Means with the same superscripts are significantly different from each other (Tukey). Parents reported their educational level and financial problems (difficulty paying bills).

Chinese girls reported higher levels of paternal education than European American girls and boys. Regarding the parenting variables, European American boys reported higher levels of maternal and paternal support than Chinese American boys. Additionally, European American girls reported higher levels of autonomy granting than Filipino American girls. These differences should be viewed with caution unless measurement equivalence is established. Gender differences within ethnic group also were found: among European Americans, boys were slightly older and reported higher levels of maternal and paternal support than girls; among Filipino Americans, boys reported higher levels of maternal support than did girls.

\section{Maternal Support}

To examine configural invariance, a one-factor solution for the five maternal support items was tested separately for boys and girls in each ethnic group. Error terms of items that were adjacent to each other in the interview questionnaire were allowed to correlate to improve model fit. As shown in Table 2.2, the one-factor solution for maternal support fit well for European American girls and boys as indicated by CFIs of 0.98 and RMSEAs and SRMRs of 0.06 or less. (A correlated error term for satisfaction with communication and satisfaction with overall relationship was added for boys, and a correlated error term for perceived closeness to mother and perceived maternal caring was added for girls.) The one-factor model also fit well for Filipino American boys and girls after adding the same correlated error term as for European American boys: CFIs were 0.97 or higher; RMSEA and SRMR were 0.06 or lower. However, the model did not fit well for Chinese Americans of either gender. For boys, the fit indices suggested good fit, but three of the five items 
Table 2.2 Fit indices for measures of maternal support, paternal support, and autonomy granting for males and females in three ethnic groups

\begin{tabular}{|c|c|c|c|c|c|}
\hline & $N$ & $X^{2}$ & $\mathrm{CFI}$ & RMSEA & SRMR \\
\hline \multicolumn{6}{|c|}{ Maternal support } \\
\hline \multicolumn{6}{|c|}{ European American } \\
\hline Boys & 3,846 & $58.08^{* *, \mathrm{a}}$ & 0.98 & 0.06 & 0.03 \\
\hline Girls & 4,152 & $52.37^{* *, \mathrm{a}}$ & 0.98 & 0.05 & 0.03 \\
\hline \multicolumn{6}{|c|}{ Chinese American } \\
\hline Boys & 134 & $2.57^{\mathrm{a}}$ & 1.00 & 0.01 & 0.05 \\
\hline Girls & 113 & $27.32^{* *}$ & 0.74 & 0.20 & 0.06 \\
\hline \multicolumn{6}{|c|}{ Filipino American } \\
\hline Boys & 216 & $7.37^{\mathrm{a}}$ & 0.97 & 0.06 & 0.02 \\
\hline Girls & 210 & $4.40^{\mathrm{a}}$ & 1.00 & 0.02 & 0.04 \\
\hline \multicolumn{6}{|c|}{ Paternal support } \\
\hline \multicolumn{6}{|c|}{ European American } \\
\hline Boys & 3,304 & $80.01^{* *, b}$ & 0.97 & 0.09 & 0.02 \\
\hline Girls & 3,344 & $52.82^{* *, \mathrm{~b}}$ & 0.98 & 0.07 & 0.02 \\
\hline \multicolumn{6}{|c|}{ Chinese American } \\
\hline Boys & 123 & $217.04^{* *}$ & 0.50 & 0.59 & 0.07 \\
\hline Girls & 105 & 6.37 & 0.99 & 0.05 & 0.02 \\
\hline \multicolumn{6}{|c|}{ Filipino American } \\
\hline Boys & 189 & $5.12^{\mathrm{a}}$ & 0.99 & 0.04 & 0.03 \\
\hline Girls & 184 & $7.94^{*, \mathrm{~b}}$ & 0.98 & 0.10 & 0.03 \\
\hline \multicolumn{6}{|c|}{ Autonomy granting ${ }^{\mathrm{c}}$} \\
\hline \multicolumn{6}{|c|}{ European American } \\
\hline Boys & 4,069 & $64.47^{* *}$ & 0.96 & 0.04 & \\
\hline Girls & 4,298 & $123.36^{* *}$ & 0.95 & 0.05 & \\
\hline \multicolumn{6}{|c|}{ Chinese American } \\
\hline Boys & 134 & 8.00 & 1.00 & 0.01 & \\
\hline Girls & 116 & $22.94^{* *}$ & 0.88 & 0.12 & \\
\hline \multicolumn{6}{|c|}{ Filipino American } \\
\hline Boys & 228 & 13.18 & 0.96 & 0.05 & \\
\hline Girls & 222 & 12.71 & 0.97 & 0.04 & \\
\hline
\end{tabular}

$* p<0.05$

** $p<0.01$

${ }^{\mathrm{a}} 1$ pair of correlated errors.

${ }^{b} 2$ pairs of correlated errors.

${ }^{\mathrm{c}}$ Based on categorical CFA; SRMR is not available.

(perceived closeness to mother, perceived maternal caring, and perceived maternal warmth) failed to load significantly on the maternal support factor. For Chinese girls, the model fit was poor, as reflected in a low CFI and a high RMSEA value.

Because evidence of configural invariance was supported for European Americans and Filipino Americans, we proceeded to examine additional aspects of factorial invariance of the maternal support measure in those two ethnic groups using multiple group CFAs. To assess weak invariance, the fit of a two-group model in which corresponding factor loadings were constrained to be equal across the two ethnic groups was compared to that of an unconstrained model in which factor 
loadings were allowed to vary across groups. Model fit statistics appear in Table 2.3; unconstrained factor loadings are reported in Table 2.4.

Table 2.3 Two-group (European and Filipino American) metric invariance for parental support and autonomy for males and females

\begin{tabular}{llllll}
\hline & $X^{2}(\mathrm{df})$ & CFI & RMSEA & SRMR & $X^{2}$ Difference (df) \\
\hline Maternal support & & & & & \\
Boys $(N=3,462)$ & & & & & \\
$\quad$ Model 1: Unconstrained & $81.00(8)$ & 0.97 & 0.07 & 0.03 & \\
$\quad$ Model 2: Weak invariance & $76.13(12)$ & 0.97 & 0.05 & 0.05 & $6.04(4)$ \\
$\quad$ Model 3: Strong invariance & $90.29(16)$ & 0.97 & 0.05 & 0.05 & $6.13(4)$ \\
$\quad$ Model 4: Strict invariance & $84.49(21)$ & 0.98 & 0.04 & 0.13 & $9.35(5)$ \\
Girls $(N=3,676)$ & & & & & \\
$\quad$ Model 1: Unconstrained & $60.68(8)$ & 0.98 & 0.06 & 0.03 & \\
$\quad$ Model 2: Weak invariance & $63.75(12)$ & 0.98 & 0.04 & 0.03 & $0.90(4)$ \\
$\quad$ Model 3: Strong invariance & $72.21(16)$ & 0.98 & 0.04 & 0.03 & $5.12(4)$ \\
$\quad$ Model 4: Strict invariance & $74.22(21)$ & 0.98 & 0.03 & 0.14 & $11.73^{*}(5)$ \\
Paternal support & & & & & \\
Boys $(N=2,804)$ & & & & & \\
$\quad$ Model 1: Unconstrained & $69.04(6)$ & 0.98 & 0.08 & 0.02 & \\
$\quad$ Model 2: Weak invariance & $90.22(10)$ & 0.97 & 0.07 & 0.09 & $16.53^{* *}(4)$ \\
Girls $(N=3,676)$ & & & & & \\
$\quad$ Model 1: Unconstrained & $61.57(6)$ & 0.98 & 0.07 & 0.02 & \multirow{2}{*}{ (4) } \\
$\quad$ Model 2: Weak invariance & $55.25(10)$ & 0.99 & 0.05 & 0.04 & $1.17(4)$ \\
$\quad$ Model 3: Strong invariance & $61.46(14)$ & 0.99 & 0.04 & 0.04 & $1.11(5)$ \\
$\quad$ Model 4: Strict invariance & $56.08(19)$ & 0.99 & 0.03 & 0.04 & \\
Autonomy granting ${ }^{a}$ & & & & & \\
Boys $(N=3,462)$ & & & & & \\
$\quad$ Model 1: Unconstrained & $67.23(18)$ & 0.97 & 0.04 & & $52.21(11)^{* * *}$ \\
$\quad$ Model 2: Weak invariance & $118.78(29)$ & 0.94 & 0.04 & & \\
\hline
\end{tabular}

${ }^{*} p<0.05,{ }^{* *} p<0.01,{ }^{* * *} p<0.001$

${ }^{a}$ Based on categorical CFA; SRMR is not available.

For European American and Filipino American boys, a chi-square difference test revealed that factor loadings for all of the maternal support items could be constrained to be equal across ethnic groups without significantly reducing model fit, supporting weak invariance (see Table 2.3). Next, we constrained the item intercepts (as well as factor loadings) for corresponding items to be equal across groups (Model 3) and compared the model fit to that of the preceding model (Model 2). These additional constraints did not result in a significant increase in chi square, so strong invariance was also supported. Finally, item error variances were constrained to be equal across groups as well. These additional constraints did not result in a significant increase in chi square, and the CFI and RMSEA indicated good model fit, supporting strict invariance. However, the SRMR was 0.13, suggesting poor model fit. Thus the support for strict invariance of the maternal support measure was qualified.

Among European American and Filipino American girls, constraining corresponding factor loadings of the maternal support items to be equal across 
Table 2.4 Standardized factor loadings of parental support for males and females in two ethnic groups

\begin{tabular}{|c|c|c|c|c|}
\hline \multirow[b]{2}{*}{ Items } & \multicolumn{2}{|l|}{ Boys } & \multicolumn{2}{|l|}{ Girls } \\
\hline & $\begin{array}{l}\text { European } \\
\text { American }\end{array}$ & $\begin{array}{l}\text { Filipino } \\
\text { American }\end{array}$ & $\begin{array}{l}\text { European } \\
\text { American }\end{array}$ & $\begin{array}{l}\text { Filipino } \\
\text { American }\end{array}$ \\
\hline \multicolumn{5}{|l|}{ Maternal support } \\
\hline How close to mother & 0.52 & 0.69 & 0.59 & 0.63 \\
\hline How much she cares about you & 0.24 & 0.25 & 0.23 & 0.22 \\
\hline Mother is warm and loving & 0.47 & 0.44 & 0.59 & 0.62 \\
\hline Satisfied with communication & 0.59 & 0.66 & 0.93 & 0.96 \\
\hline Satisfied with relationship & 0.57 & 0.51 & 0.87 & 0.84 \\
\hline \multicolumn{5}{|l|}{ Paternal support } \\
\hline How close to father & 0.66 & 0.46 & 0.79 & 0.93 \\
\hline How much he cares about you & $0.36^{\mathrm{a}}$ & $0.16^{\mathrm{a}}$ & 0.38 & 0.43 \\
\hline Father is warm and loving & 0.75 & 0.79 & 0.78 & 1.00 \\
\hline Satisfied with communication & $0.76^{\mathrm{a}}$ & $0.88^{\mathrm{a}}$ & 0.85 & 0.79 \\
\hline Satisfied with relationship & 0.75 & 0.71 & 0.85 & 0.80 \\
\hline
\end{tabular}

${ }^{\text {a}}$ Factor loadings could not be constrained to be equal between groups.

groups (Model 2) did not reduce model fit, supporting weak factorial invariance. Constraining item intercepts to be equal (Model 3) also failed to reduce model fit, so strong invariance was supported. However, constraining error variances to be equal across groups (Model 4) resulted in a significant increase in chi square as well as a high SRMR (0.14), indicating poor model fit. Thus strict invariance was not supported for girls. We examined partial strict invariance by systematically freeing error variances and comparing the fit of the partially constrained model with that of the strong invariance model (Model 3). Once the item on perceived closeness to mother was freed, the chi-square difference test was not significant. Thus, four of the five items showed strict invariance. In summary, results revealed evidence of configural, weak, and strong factorial invariance of the maternal support measure for European American and Filipino adolescents of both genders as well as qualified evidence of strict invariance. In contrast, for Chinese American adolescents, the maternal support measure failed to meet the fundamental requirement of configural invariance.

\section{Paternal Support}

Configural invariance for paternal support was examined in a similar manner, by testing a one-factor solution separately for boys and girls in each ethnic group. As shown in Table 2.2, the one-factor solution fit adequately for European American girls and boys (two correlated error terms, one for satisfaction with communication and satisfaction with overall relationship and one for closeness to father and perceived paternal caring, were added for each gender). The one-factor solution 
also fit adequately for Filipino American boys and girls (the same correlated error terms used for European Americans were added for Filipinas, whereas only the correlated error term for closeness to father and perceived paternal caring was added for Filipino American boys). For Filipino American girls, the CFI and SRMR indicated acceptable fit, but the RMSEA value approached the cut-off value of 0.10 suggesting marginal fit. In contrast, the one-factor model did not fit well for Chinese Americans of either gender. For Chinese American boys, the fit indices indicated very poor fit (low CFI; high RMSEA). For Chinese American girls, the fit indices appeared good but one of the five items, ("How much do you think your father cares about you?") failed to load significantly on the paternal support factor. Taken together, these results support configural invariance of the paternal support measure for European American and Filipino American adolescents but not for Chinese youth.

Based on these results we proceeded to examine more stringent types of factorial invariance among Filipino and European American adolescents. For boys, two-group CFAs showed that constraining factor loadings to be equal across groups resulted in a significant increase in chi square, so weak invariance was not supported (see Table 2.3 for fit statistics). Tests of partial weak invariance indicated that factor loadings of three paternal support items could be constrained to be equal across groups without a significant increase in the chi-square value (i.e., they were invariant); however, constraining the loadings for the remaining two items ("How much do you think he cares about you?" and "You are satisfied with the way your father and you communicate with each other") resulted in a significant decrement in model fit. As shown in Table 2.4, the factor loading for caring was higher for European American boys, whereas the loading for communication was higher for Filipino Americans. Because these items were not invariant only partial weak invariance was supported for European and Filipino American boys. In contrast, for Filipino American and European American girls, factor loadings, intercepts, and item error variances could each be constrained to be equal across groups without significantly reducing model fit. Thus, weak, strong, and strict factorial invariance were all supported (see Table 2.3).

\section{Autonomy Granting}

A one-factor solution was also examined to assess configural invariance in the measure of autonomy granting. In this case, we used a categorical CFA, because the items were dichotomous. The one-factor model showed an adequate fit for European American boys and girls and for Filipino American boys (see Table 2.2); however, in the other three groups one or more items failed to load significantly on the autonomy factor. (For Filipino American girls, the factor loading for the item on deciding what to eat was not significant. For Chinese American girls, loadings for the items regarding what to wear and what to eat were not significant, and for Chinese American boys, loadings for items on how much television to watch and when to go to bed on 
week nights were not significant.) Accordingly, further tests of factorial invariance were restricted to Filipino American and European American boys.

We could not assess weak invariance for the autonomy-granting measure because in categorical CFA the factor loadings and thresholds need to be constrained simultaneously. Therefore, we examined strong invariance for Filipino American and European American boys. The fit of a model in which factor loadings and thresholds were constrained to be equal across groups was compared to that of an unconstrained model in which factor loadings, item intercepts, and error variances were allowed to vary. In this case, the chi-square difference test was significant, so strong invariance was not supported (see Table 2.3). We examined partial strong invariance; however, results indicated that none of the items was invariant across groups.

In summary, results afforded strong evidence of cross-ethnic equivalence of the maternal support measure between European American and Filipino American adolescents of both genders in that configural, metric invariance, and strong invariance were supported for both boys and girls. Results regarding strict invariance were more equivocal, but partial strict invariance was found for girls and mixed evidence was found for boys. Concerning the measure of paternal support, there was evidence of strict factorial invariance between European American and Filipino American adolescent girls, but only partial weak invariance was supported for boys. For autonomy granting, there was evidence of configural invariance between European American and Filipino American boys but not between European American and Filipino American girls. There was no evidence of factorial invariance between Chinese Americans and either of the other groups on any of the parenting measures, as the basic test of configural invariance failed in each case.

\section{Discussion}

The goal of this chapter was to investigate the cross-ethnic equivalence of measures of parental support and autonomy granting across representative samples of European American, Chinese American, and Filipino American adolescents in order to elucidate possible cross-cultural similarities and differences in the meaning of these measures. To this end, we examined factorial invariance across ethnic groups separately by gender. The picture that emerged is one of considerable cross-ethnic invariance of the Add Health measures of maternal and paternal support for European Americans and Filipino Americans of both genders but not for Chinese Americans. In contrast, the evidence of cross-ethnic equivalence of the autonomy-granting measure was generally weak, suggesting that this measure may have different meanings for Asian American and European American adolescents.

Results for Filipino Americans and European Americans indicated that these two groups have similar understandings of maternal and paternal support. For both of these measures, configural invariance and either full or partial weak invariance was supported for both genders. Configural invariance suggests that two groups share a 
common frame of reference for the construct under study (Ghorpade, Hattrup, \& Lackritz, 1999). Thus, Filipino and European Americans appear to conceptualize or perceive parental support in similar ways, at least with respect to the items included in the Add Health measures. The similarity in factor structure also indicates that the dimensions of maternal or paternal support tapped by the items are similar in both ethnic groups. Additionally, the support for strong invariance of the maternal support measure for European Americans and Filipino Americans of both genders indicates that the items are weighted similarly by members of both groups in defining the underlying dimension of maternal support and that both groups use the same metric in responding to the items. Furthermore, the evidence of strong invariance indicates that scores on the latent variable underlying this measure are comparable for Filipino and European Americans, although documentation of strict invariance would be desirable before raw scores are compared.

For paternal support the evidence of strict invariance between European and Filipino American girls indicates that scale scores for these two groups have the same meaning and can be compared. In contrast, the results for boys suggest the need for greater caution in making cross-group comparisons. In particular, two paternal support items regarding caring and satisfaction with communication were not invariant and loaded more strongly for one group of boys than the other. Caring loaded more strongly for European American boys, which suggests that it is more central to their notions of paternal support; however, satisfaction with communication loaded more strongly for Filipino American boys. Prior research on Asian parents indicates that they are less likely than European American parents to express warmth (Chao, 2001a; Wu \& Chao, 2005), so we might expect a weaker loading for caring among Filipinos (as was found). However it is unclear why satisfaction with communication would be a stronger indicator for Filipino boys. Most prior research has focused on Chinese Americans, and Filipino American parents may be different (e.g., more accepting of open communication). Additional studies of this measure in Filipino samples are needed to replicate our results and to further probe the reasons that satisfaction with communication appears more central to Filipino American boys' notions of paternal support. Interestingly, $t$ tests indicated no significant ethnic differences in reported levels of either maternal or paternal support for either gender. Thus, it appears that Filipino and European American adolescents of the same gender perceive similar levels of parental support.

The picture that emerged for autonomy granting was quite different. Configural invariance was found only for Filipino and European American boys suggesting that they share the same basic dimension of autonomy granting. However, strong invariance was not supported, indicating a lack of scalar equivalence. Thus, values on this scale may not be comparable in these two groups. Filipino and European American girls showed a lack of configural invariance on the measure of autonomy granting because several items did not load significantly on the underlying factor for Filipina Americans. Possibly, these items are not relevant to Filipinas' understanding or experience of autonomy, or perhaps they form different factors reflecting distinct underlying dimensions. A more extensive measure of perceived autonomy granting would be needed to explore group differences in the number of dimensions. 
In any case, the lack of configural invariance casts doubt on the utility of this measure in studies of Filipinas and suggests that Filipina and European American girls may have different understandings of autonomy.

Perhaps the most striking finding of the present analysis is the total lack of measurement equivalence observed between Chinese Americans and the other two ethnic groups. The factor structure of all three parenting measures differed for Chinese Americans of both genders such that configural invariance was not supported. Conceptually, the results are consistent with the notion that Chinese American youth hold different concepts of parental support and autonomy granting compared to either European or Filipino American adolescents. This interpretation is consistent with prior research on Chinese parenting which indicates that distinct philosophical traditions underlie Chinese parenting, resulting in different dimensions of parenting and/or a different understanding of particular parenting behaviors (Chao, 1996; Wu \& Chao, 2005). The results support the notion that parenting behaviors are embedded in culturally based meaning systems (Greenfield, 1994; Super \& Harkness, 1986) and need to be interpreted within those systems in order to be understood. On a practical level, the results indicate that the Add Health parenting measures examined here cannot be used with confidence among Chinese American adolescents of either gender and, moreover, that comparisons of Chinese Americans and other youth based on these measures would be ill-advised.

For Chinese American boys, three maternal support items failed to load on the maternal support factor, and the fit of the one-factor paternal support model was poor; also two items failed to load significantly on the autonomy factor. For Chinese girls, the fit of the one-factor solution for maternal support was poor, and one paternal support item failed to load significantly on the paternal support factor; additionally, two autonomy items did not load on the autonomy factor. The failure of one or more items to load significantly on a factor could mean that each parenting measure comprises multiple dimensions for Chinese American youth (rather than only one) or that certain items are irrelevant to the parenting construct tapped by the measure. In contrast, poor model fit could indicate that there is no coherent pattern in the data. In the present case, an exploratory factor analysis of each parenting measure failed to identify meaningful factors among Chinese American boys or girls. However, the small number of items may have precluded finding multiple distinct dimensions. The question of multiple dimensions should be examined in future studies that employ more extensive measures of perceived maternal and paternal support and autonomy granting.

Nonetheless, examining the items that did not load significantly on the specified factor may be instructive. For Chinese boys, the items for perceived maternal caring, closeness to mother, and maternal warmth failed to load significantly on the maternal support factor. These results suggest that, for boys, the experience of maternal caring, closeness, and warmth are not strongly linked to feelings of satisfaction regarding their relationships with their mothers. Perhaps satisfaction with parent-child relationships among Chinese Americans is distinct from perceptions of warmth and closeness; rather it may depend on other characteristics such 
as fulfillment of parental role obligations. For Chinese girls, one of the four paternal support items (how much the father cares) failed to load significantly on the paternal support factor. This suggests that a girl's perception that her father cares is distinct from her experience of a supportive father and her satisfaction with the relationship. Perhaps paternal caring is simply assumed or expressed in ways that are unconnected to warmth, feeling close, and satisfaction. The results for both genders are consistent with the notion that direct expressions of warmth and affection are less central to Chinese Americans' conceptions of support (Chao, 2001a; Wu \& Chao, 2005). More broadly, the characteristics that define parent-child relationships may be culturally specific, and those assessed in the Add Health measures may be less relevant for Chinese American adolescents compared to their European American and Filipino American counterparts. Taken together, the present findings indicate that the dimensions of parental support reported by Chinese American adolescents differ from those of European American and Filipino adolescents, and this difference deserves further study.

The lack of configural invariance observed between European American girls and both groups of Asian girls on the measure of autonomy granting also merits further attention. For Filipina and Chinese American girls, some items (notably decisions about what to eat) failed to load significantly on the autonomy-granting factor, suggesting that multiple factors could be present or that certain items are irrelevant for measuring the construct. It is also interesting that two items (i.e., those regarding how much TV to watch and bedtimes) did not load significantly for Chinese American boys; perhaps these belong to a separate domain of autonomy.

Although the present study utilized a national data set with representative samples of Chinese American, Filipino American, and European American youth, certain limitations apply. The Add Health sample was based on English-speaking, in-school youth and our analysis was restricted to youth who endorsed a single race and nationality as describing them best. This led us to exclude youth who were Hispanic or who had multiple racial affiliations (e.g., biracial youth who did not identify themselves primarily as White or Asian). Furthermore, we had only adolescent self-report measures, and, although it can be argued that adolescents' perceptions of their parents' behavior are most likely to affect their adjustment (Rohner, 1986), it would be best to triangulate adolescent reports, parent reports, and observer ratings in order to fully capture parents' behavior and the meanings that parents and adolescents attribute to them. Finally, the measures of parenting were relatively brief, and it would be interesting to replicate the present results in studies using more extensive measures. It is important to remember that the present results pertain only to the constructs of parental support and autonomy granting as they were measured in the Add Health study. Aspects of parental support and autonomy granting that are salient to adolescents (especially Asian Americans) may have been omitted, affecting the results.

Despite these limitations, the present results add to the growing body of research on parenting and Asian youth and to the meager literature on measurement equivalence with Asians. Our findings suggest that the understanding of maternal and 
paternal support may be similar for European and Filipino Americans; furthermore, a shared understanding of autonomy granting seems likely for boys in these two ethnic groups but perhaps not for girls. The results further indicate that Chinese American adolescents in particular may have distinct conceptions of these constructs, which need to be elucidated. Further attention to the cultural bases of parenting practices and parent-adolescent relationships, particularly for Chinese American immigrant families, is needed: this is the focus of the two chapters that follow. To gain a richer understanding of the perspectives of Chinese and Filipino American adolescents on parental support and autonomy granting, it is important to learn how these youth define good parent-adolescent relationships, a topic we turn to in Chapters 5 and 6.

\section{References}

Agbayani-Siewert, P. (1994). Filipino American culture and family: Guidelines for practitioners. Families in Society, 75, 429-438.

Bae, W., \& Brekke, J. S. (2003). The measurement of self-esteem among Korean Americans: A cross-ethnic study. Cultural Diversity and Ethnic Minority Psychology, 9, 16-33.

Bearman, P. S., Jones, J., \& Udry, J. R. (1997). The national longitudinal study of adolescent health: Research design [WWW document], http://www.cpc.unc.edu/addhealth

Berndt, T. J., Cheung, P. C., Lau, S., \& Hau, K. (1993). Perceptions of parenting in mainland China, Taiwan, and Hong Kong: Sex differences and societal differences. Developmental Psychology, $29,156-164$.

Bond, M., \& Wang, S. (1983). Aggressive behaviour in Chinese society: The problem of maintaining order and harmony. Bulletin of the Hong Kong Psychological Society, 8, 5-25.

Byrne, B. M., Shavelson, R. J., \& Muthén, B. (1989). Testing for the equivalence of factor covariance and mean structures: The issue of partial measurement invariance. Psychological Bulletin, $105,456-466$.

Chantala, K., \& Tabor, J. (1999). Strategies to perform a design-based analysis using the Add Health data [WWW document], http://www.cpc.unc.edu/addhealth

Chao, R. K. (1994). Beyond parental control and authoritarian parenting style: Understanding Chinese parenting through the cultural notion of training. Child Development, 65, 1111-1119.

Chao, R. K. (1996). Chinese and European American mothers' beliefs about the role of parenting in children's school success. Journal of Cross-Cultural Psychology, 27, 403-423.

Chao, R. K. (2001a). Extending research on the consequences of parenting style for Chinese Americans and European Americans. Child Development, 72, 1832-1843.

Chiu, L. (1987). Child-rearing attitudes of Chinese American, Chinese American-American, and European-American mothers. International Journal of Psychology, 22, 409-419.

Crockett, L. J., Brown, J., Iturbide, M. I., Russell, S. T., \& Wilkinson-Lee, A. (2009). Conceptions of parent-adolescent relationships among Cuban American teenagers. Sex Roles, 60, 575-587.

Crockett, L. J., Brown, J., Russell, S. T., \& Shen, Y.-L. (2007). The meaning of good parentchild relationships for Mexican American adolescents. Journal of Research on Adolescence, 17, 639-668.

Crockett, L. J., Randall, B. A., Shen, Y., Russell, S. T., \& Driscoll, A. K. (2005). Measurement equivalence of the center for epidemiological studies depression scale for Latino and Anglo adolescents: A national study. Journal of Consulting and Clinical Psychology, 73, 47-58.

Fuligni, A. J. (1998). Authority, autonomy, and parent-adolescent conflict and cohesion: A study of adolescents from Mexican, Chinese, Filipino, and European backgrounds. Developmental Psychology, 34, 782-792. 
Fuligni, A. J., \& Pedersen, S. (2002). Family obligation and the transition to young adulthood. Developmental Psychology, 38, 856-868.

Ghorpade, J., Hattrup, K., \& Lackritz, J. R. (1999). The use of personality measures in crosscultural research: A test of three personality scales across two countries. Journal of Applied Psychology, 84, 670-679.

Greenfield, P. M. (1994). Independence and interdependence as developmental scripts: Implications for theory, research, and practice. In P. M. Greenfield \& R. R. Cocking (Eds.), Cross-cultural roots of minority child development (pp. 1-37), Hillsdale, NJ: Lawrence Erlbaum Associates.

Hui, C. H., \& Triandis, H. C. (1985). Measurement in cross-cultural psychology. Journal of CrossCultural Psychology, 16, 131-152.

Jöreskog, K., \& Sörbom, D. (1998). LISREL 8: Structural equation modeling with the SIMPLIS command language. Lincolnwood, IL: Scientific Software International, Inc.

Julian, T. W., McHenry, P. C., \& McKelvey, M. W. (1994). Cultural variations in parenting, perceptions of Caucasian, African American, Hispanic, and Asian American parents. Family Relations, 43, 30-37.

Kelloway, E. K. (1998). Using LISREL for structural equation modeling. Thousand Oaks, CA: Sage Publications.

Kline, R. B. (1998). Principles and practice of structural equation modeling. New York: Guilford Press.

Knight, G. P., \& Hill, N. E. (1998). Measurement equivalence in research involving minority adolescents. In V. McLoyd \& L. Steinberg (Eds.), Studying minority adolescents: Conceptual, methodological and theoretical issues (pp. 183-210). Hillsdale, NJ: Lawrence Erlbaum Associates, Inc.

Lam, C. (2003). Covert parental control: Parent-adolescent interaction and adolescent development in a Chinese American context. International Journal of Adolescence Medical Health, $15,63-77$.

Lansford, J. E., Chang, L., Dodge, K. A., Malone, P. S., Oburu, P., Palmerus, K., et al. (2005). Physical discipline and children's adjustment: Cultural normativeness as a moderator. Child Development, 76, 1129-1317.

Lau, S. Lew, W. J. F., Hau, K. T., Cheung, P. C., \& Berndt, T. J. (1990). Relations among perceived parental control, Warmth, indulgence, and family harmony of Chinese American in mainland China. Developmental Psychology, 26, 674-677.

Lin, C. C., \& Fu, V. R. (1990). A comparison of child-rearing practices among Chinese American, immigrant Chinese American, and Caucasian-American parents. Child Development, 61(2), Special Issue on Minority Children, 429-433.

Maruyama, G. M. (1998). Basics of structural equation modeling. Thousand Oaks, CA: Sage Publications.

Muthén, L. K., \& Muthén, B. O. (1998-2007). Mplus user's guide (5th ed.). Los Angeles, CA: Muthén \& Muthén.

Nomura, N., Noguchi, Y., Saito, S., \& Tezuka, I. (1995). Family characteristics and dynamics in Japan and the United States: A preliminary report from the family environment scale. International Journal of Intercultural Relations, 19, 59-86.

Pe-Pua, R., \& Protacio-Marcelino, E. (2000). Sikolohiyang Pilipino (Filipino psychology): A legacy of Virgilio G. Enriquez. Asian Journal of Social Psychology, 3, 49-71.

Rohner, R. P. (1986). The warmth dimension: Foundations of parental acceptance-rejection theory. Thousand Oaks, CA: Sage Publications, Inc.

Super, C. M., \& Harkness, S. (1986). The developmental niche: A conceptualization at the interface of child and culture. International Journal of Behavioral Development, 9, 545-569.

Udry, J. R. (1998). The national longitudinal study of adolescent health (add health), waves I \& II, 1994-1996 [machine-readable data file and documentation]. Chapel Hill, NC: Carolina Population Center, University of North Carolina. 
Vandenberg, R. J., \& Lance, C. E. (2000). A review and synthesis of the measurement invariance literature: Suggestions, practices, and recommendations for organization research. Organizational Research Methods, 3, 4-70.

Wu, C. X., \& Chao, R. K. (2005). Intergenerational cultural conflicts for Chinese American youth with immigrant parents: Norms of parental warmth and the consequences. International Journal of Behavioral Development, 29, 516-523.

Youniss, J., \& Smollar, J. (1985). Adolescents' relations with mothers, fathers, and friends. Chicago: University of Chicago Press.

Yuan, K. H., \& Bentler, P. M. (2000). Three likelihood-based methods for mean and covariance structure analysis with nonnormal missing data. In M. E. Sobel \& M. P. Becker (Eds.), Sociological methodology 2000 (pp. 165-200). Washington, DC: ASA. 